\title{
IN-PLANE CRITICAL STRENGTH OF THIN-WALLED STEEL FRAMES SUBJECTED TO VERTICAL LOADS
}

\author{
By Hiroshi NAKAI*, Susumu EMI** and Toshihiro MIKI***
}

\begin{abstract}
This paper deals with the in-plane ultimate strength of steel frames with the thin-walled box sections subjected to the vertical loads. Firstly, a numerical method for analyzing the "critical strength" of frames with the initial imperfections in elasto-plastic regions is developed on the basis of second order analysis by approximating the influences of local buckling of thin-walled column elements on the overall buckling collapse. Secondly, an experimental study is performed on the test specimens of five portal frames. Finally, the effective column lengths of frames are discussed and an approximate method to evaluate the critical strength of frames are proposed through experimental and theoretical studies.
\end{abstract}

\section{INTRODUCTION}

In the Japanese Specification for Highway Bridges (JSHB) ${ }^{1}$, the ultimate strength of steel frames with the thin-walled box sections such as steel piers and pylons of cable-stayed or suspension bridges can be evaluated on the basis of the ultimate strength curves of hinged-end column of which length corresponds to the effective column length of frame given by the function of flexural rigidity and boundary conditions of beam and column. The similar design provisions are provided in other foreign specifications as are indicated in $\mathrm{ERSC}^{2)}{ }^{\text {3) }}$ and DIN 188004).

Numerous theoretical and experimental studies ${ }^{5)}$ (8) for the centrally loaded columns have been carried out and have proposed the several ultimate strength curves by considering the influences of initial imperfections and local bucklings of plate elements. However, it is necessary to clarify the effective column lengths of frames in inelastic buckling regions, because the effective column langths of frames in the above specifications have been derived by a linear bifurcation theory ${ }^{9)}$ without considering the initial imperfections.

Although there have been many experimental works ${ }^{10), 11}$ on the elasto-plastic buckling stability of frames with the compact sections for the purpose of applications to the plastic design methods, the experimental data on the thin-walled frames can not scarcely be found hitherto.

In this study, an analytical method ${ }^{12)}$ based upon elasto-plastic and second order theory for the portal

* Member of JSCE, Dr. Eng., Professor, Dept. of Civil Eng., Osaka City University (Sugimoto 3-3-138, Sumiyoshi-ku, Osaka 558)

** Member of JSCE, Chief Eng., Central Office of Hanshin Expressway Public Corporation (Kitakyutaro-chou 4, Higashi-ku, Osaka 541)

*** Member of JSCE, M. Eng., Research Associate, Dept. of Civil Eng., Osaka City University (Sugimoto 3-3-138, Sumiyoshi-ku, Osaka 558) 
frames with the thin-walled box sections are predicated by approximating the influences of local buckling of column elements on overall buckling collapse of frames. The tests on five portal frames are undertaken in order to check the validity of this method. From these analyses and experiments, the lower bounds of ultimate strength referred to as the "critical strength" of portal frames are clarified. Then, an approximate method for this critical strength of frames is detailed and the corresponding formula for determining the effective column lengths is proposed.

\section{ELASTO-PLASTIC AND SECOND ORDER ANALYSIS OF FRAME WITH THIN- WALLED CROSS-SECTION}

\section{(1) Analytical model}

A portal frame consisted of thin-walled box section, shown in Fig. 1, and subjected to vertical loads, shown in Fig. 2 (a), is analyzed in this paper. It is assumed in this frame that both the columns undergo almost the same compressive forces, $P$, the deflection curve of a cross-beam becomes anti-symmetrical and this beam remains elastic up to the ultimate state of frame. Thus, the cantilever column with rotational restraint, $K_{\varphi}$, and a compressive load $P$ at the top can be provided as an analytical model as illustrated in Fig. 2 (b).

If the stiffness ratio of column to beam, $K$, is defined by;

$$
K=\left(I_{c y} / h\right) \cdot\left(l / I_{b y}\right)
$$

the rotational restraint, $K_{\varphi}$, can be written as follows;

$$
K_{\varphi}=(1 / K) \cdot\left(6 E I_{c y} / h\right)
$$

where $I_{c y}, I_{b y}$ : geometrical moments of inertia of column and beam, respectively, $h, l:$ height and span of frame, respectively, and $E$ : Young's modulus $\left(=2.1 \times 10^{5} \mathrm{MPa}\right)$.

(2) Initial imperfection and residual stress

The frames are assumed to have the initial deflection modes $\bar{w}_{0}(x)$, shown in Fig. $2(\mathrm{a})$, similar to the elastic buckling mode,

$$
\bar{w}_{0}(x)=\delta_{o c} \cdot\left\{1-\cos \left(x / h_{e}\right)\right\} \text {. }
$$

in order to evaluate the lowest ultimate strength of frames, where $h_{e}:$ effective column length in frames based on the elastic buckling theory ${ }^{13)}$. The values of $\delta_{0 c}$ are taken as $h_{e} / 1000$ which corresponds to the fabrication tolerance of JSHB for the column members with the length, $h_{e}$. Then, the variations of initial deflection $\delta_{0}$ at the top of column and the effective length factor $\beta_{e}\left(=h_{e} / h\right)$ with the stiffness ratio $K$ can be listed in Table 1.

The residual stress distributions adopted in this analysis is such a pattern as shown in Fig. 1, in which the compressive residual stress, $\sigma_{r c}$, is taken as 0.4 times of the yield stress, $\sigma_{y}$.

\section{(3) Analytical method}

The transfer matrix method based on the second order analysis ${ }^{12)}$ is adopted to an analytical model. The

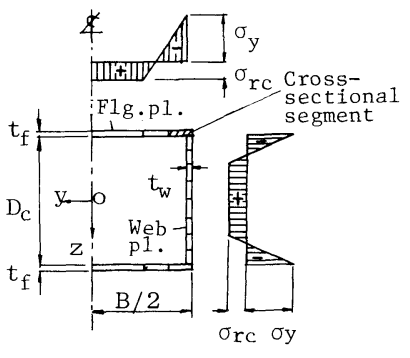

Fig. 1 Residual stresses and cross-sectional segment in box section.

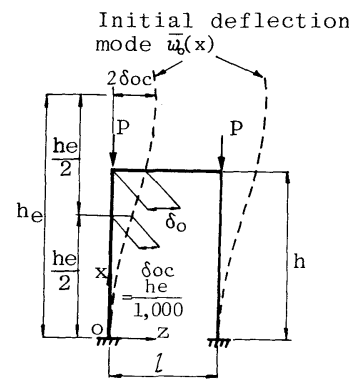

(a) Portal frame with initial imperfection

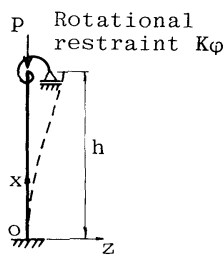

(b) Analytical model

Fig. 2 Analytical model of portal frame subjected to vertical loads. 
Table 1 Variations of initial deflection $\delta_{D} / h$ and effective length ratio $\beta_{e}$ due to stiffness ratio $K$ of beam and column.

\begin{tabular}{|c|c|c|c|c|c|c|c|}
\hline Items & 0 & 1 & 2 & 3 & 4 & 5 & $\infty$ \\
\hline $\begin{array}{c}\text { Effective length ratio } \\
\beta_{e}=\text { he/h }\end{array}$ & 1.0 & 1.157 & 1.279 & 1.373 & 1.445 & 1.502 & 2.0 \\
\hline $\begin{array}{l}\text { Initial deflection } \delta_{0} / \mathrm{h} \\
\text { at top of column }\end{array}$ & $\frac{1}{500}$ & $\frac{1}{452}$ & $\frac{1}{441}$ & $\frac{1}{439}$ & $\frac{1}{442}$ & $\frac{1}{445}$ & $\frac{1}{500}$ \\
\hline
\end{tabular}

material is assumed to be perfectly elasto-plastic and their nonlinearlity is considered by dividing the column sections into the small segments as shown in Fig. 1 and by taking the effective flexural rigidities calculated from the elastic zones of cross-sectional segments.

\section{(4) Ultimate strength}

When a local buckling behavior of column sections is taken into account in overall buckling analysis of frame, rigorous and troublesome procedures will be necessary. The ultimate strength of frames accompanied by this local buckling is, then, evaluated by introducing the following two assumptions ${ }^{7}$;

(i) The decreases of flexural rigidities of column sections due to the initial deflections of plate elements are smaller than the ones due to the propagations of plastic zones caused by the residual stresses.

(ii) The uniaxial and flexural rigidities of a column section are nearly equal to zero as soon as a column sections reduces to the ultimate state, and then the frame reaches the ultimate state, because of the fact that the column is composed of thin-walled box section.

The ultimate state of column sections can be decided by using a interaction curve of thin-walled box stub-columns subjected to compression and bending as is proposed by Ref.7) as follows;

$$
\left.\begin{array}{rlr}
\bar{M}_{i}= & \bar{M}_{f p} / \bar{P}_{f y} \cdot\left(k_{p l}-\bar{P}\right), \\
= & \left(1 / k_{p l}\right)^{2} \cdot\left\{2\left(1-\bar{M}_{f p}\right)-\left(\bar{M}_{f p} \cdot \bar{P}_{w y}\right) / \bar{P}_{f y}\right\} \cdot\left(\bar{P} / \bar{P}_{w y}\right)^{3} & \\
& -\left(1 / k_{p l}\right) \cdot\left\{3\left(1-\bar{M}_{f p}\right)-\left(\bar{M}_{f p} \cdot \bar{P}_{w y}\right) / \bar{P}_{f y}\right\} \cdot\left(\bar{P} / \bar{P}_{w y}\right)^{2}+k_{p l}, P<k_{p l} \cdot P_{w y}
\end{array}\right\} .
$$

where

$$
\begin{aligned}
& \bar{M}_{i}=M_{i} / M_{p}, \bar{P}=P / P_{y}, \bar{P}_{f y}=P_{f y} / P_{y}, \bar{P}_{w y}=P_{w y} / P_{y}, \bar{M}_{f p}=M_{f p} / M_{p} \\
& P_{f y}=2 B \cdot t_{f} \cdot \sigma_{y}, P_{w y}=2 D_{c} \cdot t_{w} \cdot \sigma_{y}, M_{f p}=P_{f y} \cdot\left(D_{c}+t_{f}\right) / 2, P_{y}=P_{f y}+P_{w y} \\
& M_{p}=P_{f y} \cdot\left(D_{c}+t_{f}\right) / 2+D_{c}^{2} \cdot t_{w} \cdot \sigma_{y} / 2
\end{aligned}
$$

in which $M_{i}, P$ : bending moment and compressive force acting on the column element, $i$, of a load step, respectively, $M_{p}, P_{y}$ : fully-plastic moment and squash force of the column sections, respectively.

The parameter, $k_{p l}$, is the ultimate strength of stub-columns under uniaxial compression, which can be decided by using the plate slenderness,

$$
R_{f w}=\frac{B}{t_{f}} \cdot \sqrt{\frac{12\left(1-\mu^{2}\right)}{k_{f w} \cdot \pi^{2}}} \cdot \sqrt{\frac{\sigma_{y}}{E}}
$$

of stub-columns and can be calculated from the following equation ${ }^{15)}$;

$$
\left.\begin{array}{rlr}
k_{\rho l} & =1.0, & \left(R_{f w} \leq 0.3\right) \\
& =0.542 \cdot R_{f w}^{3}-1.249 \cdot R_{f w}^{2}+0.412 \cdot R_{f w}+0.968, & \left(0.3<R_{f w} \leq 1.3\right)
\end{array}\right\}
$$

where

$$
k_{f w}=\frac{\left(\alpha_{f}+1 / \alpha_{f}\right)^{2}+\left(t_{w} / t_{f}\right)^{3} \cdot\left(D_{c} / B\right) \cdot\left(\alpha_{w}+1 / \alpha_{w}\right)^{2}}{1+\left(D_{c} / B\right)^{3} \cdot\left(t_{w} / t_{f}\right)}, \alpha_{f}=a / B, \alpha_{w}=a / D_{c}, a=B \cdot\left\{\frac{1+\left(D_{c} / B\right)^{3} \cdot\left(t_{w} / t_{f}\right)^{3}}{1+\left(B / D_{c}\right) \cdot\left(t_{w} / t_{f}\right)^{3}}\right\}^{\frac{1}{4}}
$$

in which $B, t_{f}$ : width and thickness of the flange plate, respectively, $D_{c}, t_{w}$ : height and thickness of the web plate, respectively, $\mu$ : Poisson's ratio $(=0.3)$ and $\sigma_{y}$ : yield stress of columns.

Thus, the ultimate strength of frames can be obtained by using the transfer matrix method as the smaller load of the two ultimate states; i. e. ( i ) the instability of frames in which the sway displacements at the top of columns become extreme value, (ii) the ultimate state of column section which corresponds to Eq. (4). 


\section{EXPERIMENTAL STUDY}

\section{(1) Test specimen}

Buckling tests were conducted on the five portal frames F $1 \sim \mathrm{F} 5$ with the thin-walled box sections shown in Figs. 3 and 4. The dimensions and cross-sectional properties of test specimens are listed in Table

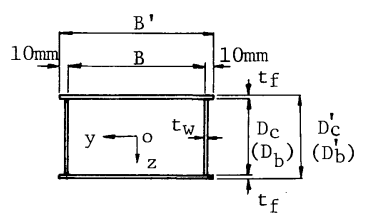

Fig. 3 Cross-section of column (beam) in test frame.

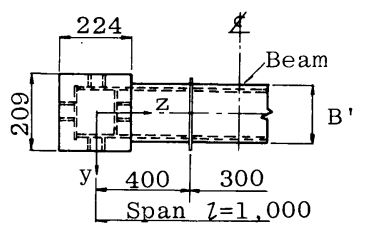

(a) Plan

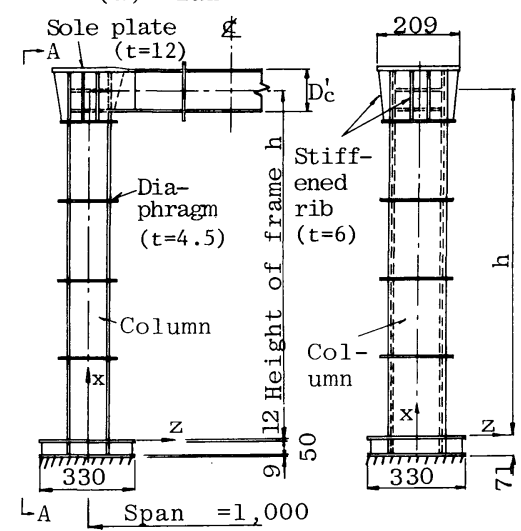

(b) Side elevation (c) Section

(Dimension: $\mathrm{mm}$ )

Fig. 4 Details of test frames.
Table 3 Yield points $\sigma_{y}$ of columns in test frames.

\begin{tabular}{c|c|c|c|c|c}
\hline$\sigma_{\mathrm{y}}$ & F1 & F2 & F3 & F4 & F5 \\
\hline MPa & 296 & 296 & 292 & 292 & 273 \\
\hline
\end{tabular}

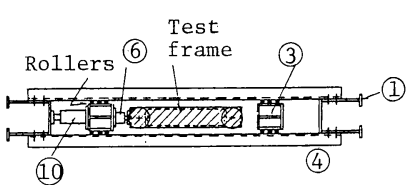

(a) Plan (A-A)

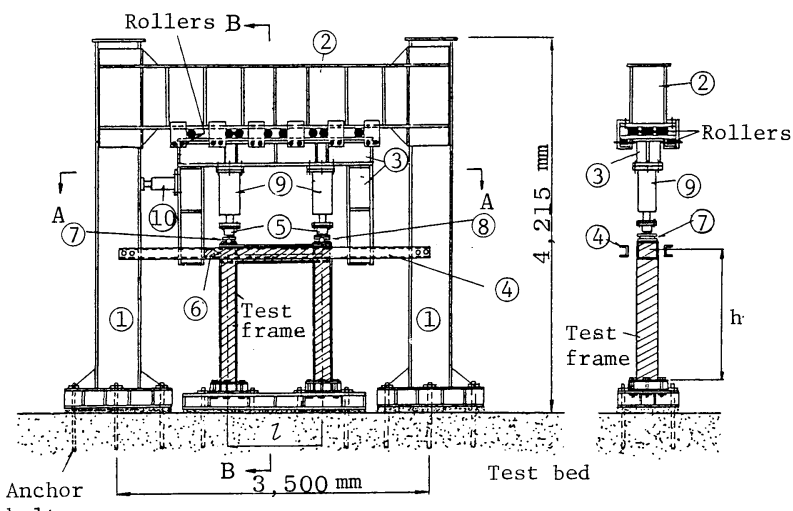

(b) Side elevation

(c) Section $B-B$

(1) Column of loading frame, (2) Beam of loading frame, (3) Loading beam, (4) Beam for preventing out-of-deformation of test frames, (5) $980 \mathrm{KN}$ load cell, (6) $9.8 \mathrm{KN}$ load cell, (7) Pin-shoe (fixed), (8) Pin-shoe(movable), (9) $980 \mathrm{KN}$ hydrauric jack (10) $295 \mathrm{KN}$ hydrauric jack

Fig. 5 Experimental device for test frames.

Table 2 Dimensions, cross-sectional properties and buckling parameters of test frames (SS 41).

\begin{tabular}{|c|c|c|c|c|c|c|c|c|c|c|c|c|c|c|}
\hline \multirow{2}{*}{$\begin{array}{l}\text { Items } \\
\text { Test } \\
\text { frames }\end{array}$} & \multicolumn{7}{|c|}{ Dimensions } & \multicolumn{3}{|c|}{$\begin{array}{l}\text { Cross-sectiona1 } \\
\text { properties }\end{array}$} & \multicolumn{4}{|c|}{$\begin{array}{l}\text { Buckling } \\
\text { parameters }\end{array}$} \\
\hline & $\begin{array}{c}B^{\prime} \\
(\mathrm{mm})\end{array}$ & $\begin{array}{l}\mathrm{D}_{\mathrm{C}}^{\prime} \\
(\mathrm{mm})\end{array}$ & $\begin{array}{c}\mathrm{Db}^{\prime} \\
(\mathrm{mm})\end{array}$ & $\underset{(\mathrm{mm})}{\mathrm{t}_{\mathrm{f}}}$ & $\begin{array}{c}{ }^{t_{W}} \\
(\mathrm{~mm})\end{array}$ & $\begin{array}{c}2 \\
(\mathrm{~mm})\end{array}$ & $\begin{array}{c}\mathrm{h} \\
(\mathrm{mm})\end{array}$ & $\begin{array}{c}\mathrm{Ac}(\mathrm{Ab}) \\
\left(\mathrm{cm}^{2}\right)\end{array}$ & $\underset{\left(\mathrm{cm}^{4}\right)}{I_{c y}\left(I_{b y}\right)}$ & $\mathrm{r}_{\mathrm{cy}}\left(\mathrm{r}_{\mathrm{by}}\right)$ & $\mathrm{K}$ & $\mathrm{R}_{\mathrm{f}}$ & $\mathrm{R}_{\mathrm{fw}}$ & $\bar{\lambda}_{\mathrm{y}}$ \\
\hline F1-0.5-0.3 & 170 & 102 & 106 & 5.88 & 4.46 & 1,000 & 924 & $\begin{array}{c}28.1 \\
(28.5)\end{array}$ & $\begin{array}{c}520.8 \\
(569.5) \\
\end{array}$ & $\begin{array}{c}4.30 \\
(3.67)\end{array}$ & 0.99 & 0.52 & 0.49 & 0.30 \\
\hline $\mathrm{F} 2-0.5-0.5$ & 171 & 102 & 87 & 5.88 & 4.46 & 1,000 & 1,541 & $\begin{array}{c}28.1 \\
(26.7)\end{array}$ & $\begin{array}{c}520.4 \\
(357.4)\end{array}$ & $\begin{array}{c}4.30 \\
(3.66)\end{array}$ & 0.95 & 0.52 & 0.49 & 0.50 \\
\hline F3-0.7-0.3 & 178 & 104 & 109 & 4.49 & 4.47 & 1,001 & 933 & $\begin{array}{c}24.5 \\
(24.9)\end{array}$ & $\begin{array}{c}462.4 \\
(512.1)\end{array}$ & $\begin{array}{c}4.34 \\
(4.54)\end{array}$ & 0.97 & 0.70 & 0.56 & 0.30 \\
\hline$F 4-0.7-0.5$ & 178 & 104 & 87 & 4.49 & 4.47 & 999 & 1,554 & $\begin{array}{c}24.5 \\
(22.9)\end{array}$ & $\begin{array}{c}463.4 \\
(308.4)\end{array}$ & $\begin{array}{c}4.35 \\
(3.67)\end{array}$ & 0.97 & 0.70 & 0.62 & 0.50 \\
\hline F5-0.7-0.7 & 178 & 77 & 62 & 4.36 & 4.36 & 1,000 & 1,628 & $\begin{array}{c}21.5 \\
(20.2)\end{array}$ & $\begin{array}{c}226.9 \\
(137.7)\end{array}$ & $\begin{array}{c}3.25 \\
(2.63)\end{array}$ & 1.00 & 0.67 & 0.61 & 0.65 \\
\hline
\end{tabular}

Notes $B^{\prime}, D_{c}^{\prime}, D_{b}^{\prime}, t_{f}, t_{w}, Z, h$ : see Fig. 3 Fig. 4. $A_{C}, A_{b}$ : cross-sectional area of column and beam, respectively. $\mathrm{I}_{\mathrm{cy}}, \mathrm{I}_{\mathrm{by}}$ : geometrical moment of inertia of column and beam, respectively. $\mathrm{r}_{\mathrm{cy}}, \mathrm{r}_{\mathrm{by}}$ : radius of gyration of column and beam, respectively. K: Eq:(1). $\mathrm{R}_{\mathrm{f}}$ : Eq. (9) $\mathrm{R}_{\mathrm{fw}}: \mathrm{Eq} \cdot(6), \overline{\lambda y}: \mathrm{Eq} \cdot(10)$ 
2. The mild steels with thicknesses 4.5 and $6 \mathrm{~mm}$ made of steel grade SS 41 were used. The dimensions of test specimens are decided so as to satisfy the stiffness ratio, $K \cong 1.0$, the plate slenderness of flange plates, $R_{f}=0.5 \sim 0.7$ and the slenderness parameter of columns, $\bar{\lambda}_{y}=0.3 \sim 0.7$, based on the preliminary survey of the actual steel piers ${ }^{14)}$, in which $R_{f}$ and $\bar{\lambda}_{y}$ are defined as follows ${ }^{1)}$;

$$
\begin{aligned}
& R_{f}=\frac{B}{t_{f}} \cdot \sqrt{\frac{12\left(1-\mu^{2}\right)}{k \pi^{2}}} \cdot \sqrt{\frac{\sigma_{y}}{E}} \\
& \bar{\lambda}_{y}=\frac{\beta_{e} \cdot h}{r_{c y}} \cdot \frac{1}{\pi} \cdot \sqrt{\frac{\sigma_{y}}{E}}
\end{aligned}
$$

where $k$ : buckling coefficient of the isolated plate $(=4.0), r_{c y}$ : radius of gyration of box section. The symbol of test specimens $\mathrm{F} 1 \sim \mathrm{F} 5$, shown in Table 2, is categorized as follows;

$\begin{aligned} & \text { F } 120.7-0.5 \text { Slenderness parameter of columns, } \\ & \text { Plate slenderness of flange plates, } R_{f} \\ & \text { No. of test specimen (F 1 F 5) }\end{aligned}$

\section{(2) Mechanical property}

The tensile tests carried out on the coupon specimens showed that the average Young's modulus $E=$ $2.06 \times 10^{5} \mathrm{MPa}$ and average Poisson's ratio $\mu=0.28$. The average of static yield stress of steel materials for columns is listed in Table 3.

\section{( 3 ) Loading device}

The details of experimental device can be shown in Fig. 5. This device is designed to test the frames under the free condition for sway displacements. Then, the frictions by the vertical loads $P$ at the main jacks (9) (each capacity $100 \mathrm{tf}(980 \mathrm{KN})$ ) can be removed by not only the rollers inserted between loading beam (2) and loading frame (3), but also the application of infinitesimal sway load $P / 200$ by the additional jack (11) (capacity $30 \mathrm{tf}(295 \mathrm{KN}))$. The fixed and movable shoes (7) and (8) were also set up so as to unrestrain the rotations at the top of column in the test frames.

Accuracy of the expected performance of this device was checked by the test in elastic regions. As a result, the coefficient of friction at the rollers on the main jacks (9) was found to be less than 0.002 . In the experimental study, the vertical and horizontal loads were gradually increased up to the failure of test specimens.

\section{(4) Test result}

\section{a) Initial imperfections}

The initial deflections at the center of columns and their flange plates were measured prior to the collapse tests.

All the specimens had the initial deflection modes as plotted in Fig. 6 (a). The values of $\delta_{0} / h$ at the top of frames were within the ranges from $1 / 940$ to $1 / 230$ and their average was $1 / 492$ which corresponds to the

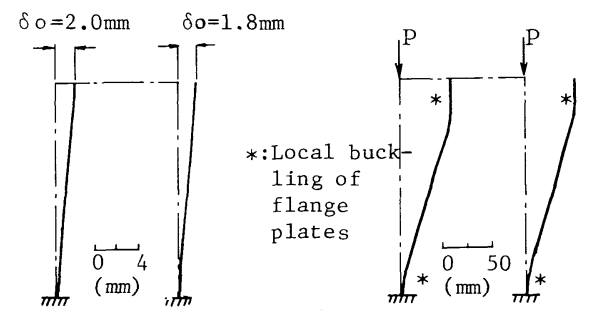

(a) Initial deflection mode

(b) Buckling mode

Fig. 6 Initial deflection mode and buckling mode of test frame $\mathrm{F} 5-0.7-0.7$.

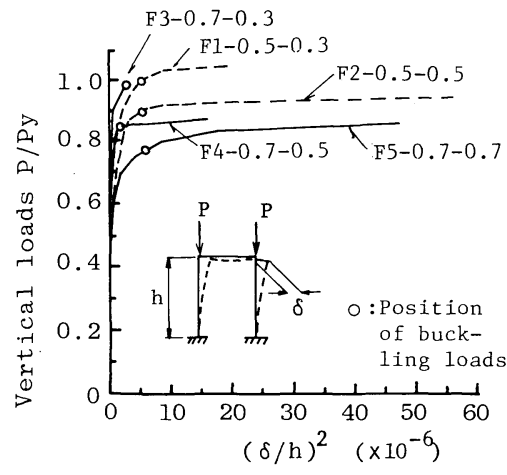

Fig. $7 P-\delta^{2}$ curves of test frames. 
Table 4 Test results of critical strength $P_{c r u} / P_{y}$ and $P_{u} / P_{y}$.

\begin{tabular}{|l|c|c|c|c|}
\hline $\begin{array}{l}\text { Items } \\
\text { Test. } \\
\text { frames }\end{array}$ & $\begin{array}{l}\text { Slender- } \\
\text { ness } \\
\text { parame- } \\
\text { ters } \bar{\lambda}_{\mathrm{y}}\end{array}$ & $\begin{array}{l}\text { Buck1ing } \\
\text { strength } \\
\text { Pcru }\end{array}$ & $\begin{array}{l}\text { U1timate } \\
\text { strength }\end{array}$ & $\begin{array}{l}\text { Difference } \\
\text { between (1) } \\
\text { and (2) } \\
\text { Py }:(2)\end{array}$ \\
\hline F1-0.5-0.3 & 0.30 & 1.010 & 1.046 & 3.6 \\
\hline F2-0.5-0.5 & 0.50 & 0.900 & 0.946 & 5.2 \\
\hline F3-0.7-0.3 & 0.30 & 0.985 & 0.985 & 0 \\
\hline F4-0.7-0.5 & 0.50 & 0.850 & 0.887 & 4.4 \\
\hline F5-0.7-0.7 & 0.65 & 0.780 & 0.867 & 11.2 \\
\hline
\end{tabular}

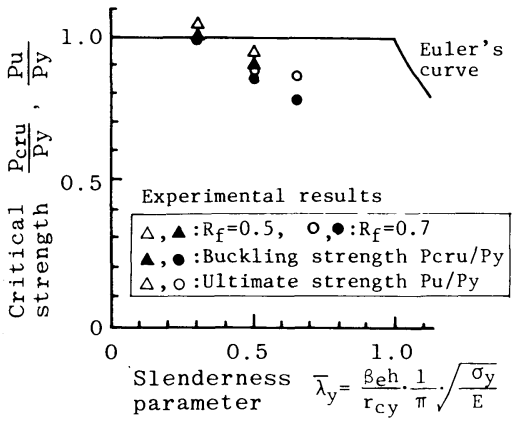

Fig. 8 Relationships between critical strength $P_{c r u} / P_{y}$, $P_{u} / P_{y}$ and slenderness parameter $\bar{\lambda}_{y}$.

assumed values in Table 1. The maximum initial deflections in flange plates was less than the tolerance value, $B / 150$, of JSHB and the average was $0.345 \cdot(B / 150)$.

b) Buckling modes

The buckling mode of test specimen $\mathrm{F} 5$ after test is sketched in Fig. 6 (b) together with the initial deflection mode. All the test specimens showed the sway buckling modes and the local buckling at the flange plates near the tops and bases of columns was also observed.

c) Buckling behaviors

The relationships between the vertical loads, $P$, and sway displacements, $\delta$, were plotted in the form of $P-\delta^{2}$ curves as shown in Fig. 7, where $P$ and $\delta$ are non-dimensionalized by the squash force of columns, $P_{y}$, and height of frames, $h$, respectively. The buckling load $P_{c r u}$ is also defined by the condition where the square of sway displacement, $\delta^{2}$, begins to increase enormously and their points are marked by the symbol, $\bigcirc$, in $P-\delta^{2}$ curves.

The $P-\delta^{2}$ curves of test specimens $\mathrm{F} 3$ and $\mathrm{F} 4$ snap just before the ultimate loads and behave as the bifurcation buckling. These mean that the frames will yield at the same time in the ultimate states of column sections, since the plate slenderness, $R_{f}$, are relatively large $(\cong 0.7)$. While, $\delta^{2}$ for the test specimen F 5 , begins to bow gradually at $P / P_{y} \cong 0.6$ and this specimen collapses at $P / P_{y} \cong 0$. 78. By comparing test specimen $\mathrm{F} 5$ with $\mathrm{F} 3$ and $\mathrm{F} 4, \mathrm{~F} 5$ has much more redundant strength from the buckling loads up to the ultimate loads. It seems that the buckling loads of frames with large slenderness parameter $\bar{\lambda}_{y}$ become lower, because the reduction of flexural rigidities of columns due to the residual stresses have a great influence upon the load-displacement relationships of frames.

It is also noted from the strain distributions in column sections that the flange plates at the base parts of frames is buckled before the ultimate loads. Their local buckling loads were prior to the ultimate loads, $P_{u}$, in the test specimens $\mathrm{F} 1$ and $\mathrm{F} 2$, and the values of test specimens $\mathrm{F} 3 \sim \mathrm{F} 5$ were smaller than $P_{u}$ by 5 $\sim 15 \%$.

\section{d) Critical strength}

The test results of buckling strength $P_{c r u} / P_{y}$ and ultimate strength $P_{u} / P_{y}$ are listed in Table 4 . These strengths are also plotted as a function of the slenderness parameter $\bar{\lambda}_{y}$ as shown in Fig. 8 .

In the test specimens F $3 \sim \mathrm{F} 5, P_{c r u}$ and $P_{u}$ are smaller than $P_{y}$ by $2 \sim 22 \%$ and $2 \sim 13 \%$, respectively, and decrease gradually in accordance with the increase of $\bar{\lambda}_{y}$. By comparing the ultimate strength of test specimen $\mathrm{F} 2$ with $\mathrm{F} 4$, the latter having the large plate slenderness $R_{f}(\cong 0.7)$ is smaller than the former $\left(R_{f} \cong 0.5\right)$ by $6 \%$.

In the specimens, $\mathrm{F} 1$ and $\mathrm{F} 2$ as well as $\mathrm{F} 3 \sim \mathrm{F} 5$, the differences between $P_{c r u}$ and $P_{u}$ are about $4 \sim 5 \%$ and $0 \sim 11 \%$, respectively. Then, the redundant strengths after the buckling loads become large in accordance with the increase of $\bar{\lambda}_{y}$. This indicates that the rigidities of frames are sensitive to the decreases of rigidities of columns due to the residual stresses as is mentioned in the above. 


\section{PARAMETRIC STUDY ON CRITICAL STRENGTH OF FRAME}

The critical strength of portal frames with the same cross-sectional dimensions as the test specimen $\mathrm{F} 4\left(R_{f} \cong 0.7\right)$ in Table 5 were analyzed by changing stiffness ratio $K$ in the ranges of $1 \sim 5$ and slenderness parameters,

$$
\bar{\lambda}_{0 y}=\frac{h}{r_{c y}} \cdot \frac{1}{\pi} \cdot \sqrt{\frac{\sigma_{y}}{E}}
$$

equal to $0.15 \sim 0.9$ under some variations of frame height, $h$.

\section{(1) $\boldsymbol{P}-\boldsymbol{\delta}$ curve}

The $P-\delta$ curves of frames for $K=3$ are illustrated in Fig. 9, where the three critical strengths $P_{c r u} / P_{y}, P_{u l} / P_{y}$ and $P_{u} / P_{y}$ (thereafter, their representatives are referred to as $P_{c r} / P_{y}$ ) are shown in this figure. $P_{c r u} / P_{y}$ means the buckling strength obtained by $P-\delta^{2}$ curves and $P_{u l} / P_{y}$ designates the ultimate strength for the local buckling loads of a column section, $P_{u} / P_{y}$ being the ultimate strength for the fully-plastic state of a column section or unstable state of frame.

As is seen from this figure, the frames with $\bar{\lambda}_{0 y}=0.15 \sim 0.45$ reduce to the ultimate states caused by the local buckling of column sections and $P_{u l} / P_{y}$ is smallest of three critical strengths. While, the frames with $\bar{\lambda}_{0 y}=0.6 \sim 0.9$ tend to bow rapidly prior to $P_{u l} / P_{y}$, thus $P_{c r u} / P_{y}$ gives the smallest critical strength.

( 2 ) Lower bound of critical strength $\boldsymbol{P}_{c r} / \boldsymbol{P}_{y}$

The variations of critical strengths $P_{c r} / P_{y}$ due to $K$ and $\bar{\lambda}_{0 y}$ are listed in Table 6 . The relationships

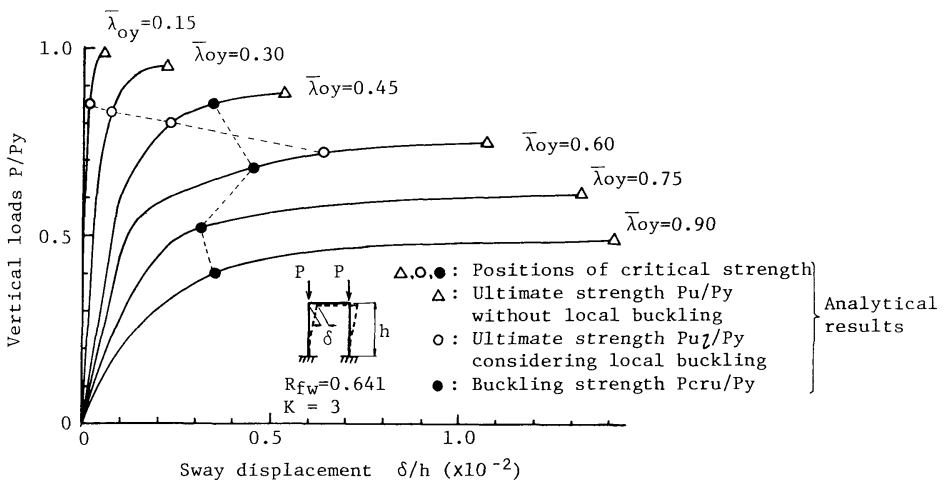

Fig. $9 \quad P-\delta$ curves and critical strength of frames.

Table 5 Column section of analytical frames.

\begin{tabular}{c|c|c|c}
\hline$B(\mathrm{~mm})$ & $\mathrm{t}_{\mathrm{f}}(\mathrm{mm})$ & $\mathrm{D}_{\mathrm{C}}(\mathrm{mm})$ & $\mathrm{t}_{\mathrm{W}}(\mathrm{mm})$ \\
\hline 162.5 & 4.5 & 104 & 4.5 \\
\hline
\end{tabular}

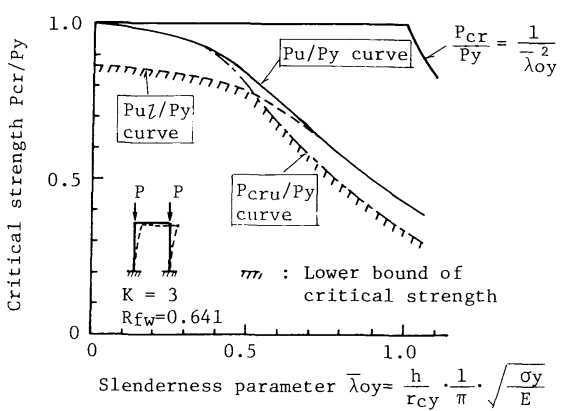

Fig. 10 Variations of critical strength due to slenderness parameter of frames.
Table 6 Variations of critical strength $P_{c r} / P_{y}$ due to stiffness ratio $K$ and slenderness parameter $\bar{\lambda}_{0 y}$

\begin{tabular}{|c|c|c|c|c|c|c|c|}
\hline \multicolumn{2}{|c|}{$\widehat{P C r}_{K} \bar{\lambda}_{\text {oy }}$} & 0.15 & 0.30 & 0.45 & 0.60 & 0.75 & 0.90 \\
\hline \multirow{4}{*}{$\frac{\mathrm{Pu}}{\mathrm{Py}}$} & 0 & 0.984 & 0.959 & 0.909 & 0.828 & 0.738 & 0.647 \\
\hline & 1 & 0.984 & 0.958 & 0.902 & 0.802 & 0.695 & 0.592 \\
\hline & 3 & 0.983 & 0.953 & 0.880 & 0.752 & 0.617 & 0.494 \\
\hline & 5 & 0.983 & 0.947 & 0.852 & 0.702 & 0.557 & 0.432 \\
\hline \multirow{4}{*}{$\frac{\mathrm{Pul}}{\mathrm{Py}}$} & 0. & 0.852 & 0.839 & 0.820 & 0.783 & 0.716 & 0.644 \\
\hline & 1 & 0.852 & 0.839 & 0.814 & 0.763 & 0.677 & 0.592 \\
\hline & 3 & {$\left[\begin{array}{l}0.852 \\
0.82\end{array}\right.$} & 0.833 & $\begin{array}{l}802 \\
\end{array}$ & 0.721 & 0.613 & 0.494 \\
\hline & 5 & {$[0.848$} & 0.830 & 0.786 & 0.682 & 0.557 & 0.432 \\
\hline \multirow{4}{*}{$\frac{P_{c r u}}{P_{y}}$} & 0 & - & 0.957 & 0.900 & 0.800 & 0.675 & 0.550 \\
\hline & 1 & - & 0.956 & 0.888 & 0.775 & 0.620 & 0.500 \\
\hline & 3 & - & 0.950 & 0.850 & 0.675 & 0.525 & 0.400 \\
\hline & 5 & - & 0.946 & 0.825 & 0.625 & 0450 & 0.350 \\
\hline
\end{tabular}

cal strength 
between $P_{c r} / P_{y}$ and $\bar{\lambda}_{0 y}$ of the frames for $K=3$ are plotted in Fig. 10.

From this figure, it seems that the lower bounds of $P_{c r} / P_{y}$ are given by $P_{u l} / P_{y}$ in the ranges where $\bar{\lambda}_{0 y}=0$ $\sim 0.52$ and $P_{c r u} / P_{y}$ in the ranges where $\bar{\lambda}_{0 y}>0.52$. Therefore, it is important to clarify the buckling strength in order to set the lower bounds of critical strength of frames.

\section{(3) Variation of buckling strength}

The buckling strength $P_{c r u} / P_{y}$ is plotted as a function of $\bar{\lambda}_{0 y}$ as shown in Fig. 11 from Table 6, in which the fundamental ultimate strength curve of centrally loaded hinged-end columns by our analysis is also shown in this figure.

It can be seen from this figure that the decreases of $P_{c r u} / P_{y}$ are predominant in accordance with the increases of $K$ and $\bar{\lambda}_{0 y}$.

\section{EFFECTIVE COLUMN LENGTH AND CALCULATION METHOD FOR CRITICAL STRENGTH OF FRAME}

\section{(1) Effective column length based on buckling strength}

In order to obtain the effective column length, $h_{e}$, of frames, the variations due to two slenderness parameters, $\bar{\lambda}_{0 y}$ and $\bar{\lambda}_{y}$, were investigated from Table 6 . These results can be plotted in Fig. 12, where the column strength is obtained by the curve $P_{u 0} / P_{y}$ in Fig. 11. From this figure, the effective length factor, $\beta$, can be defined as the slope of a line between origin $(0,0)$ and point $\left(\bar{\lambda}_{0 y}, \bar{\lambda}_{y}\right)$.

Although $\beta=1.0$ in the ranges where $\bar{\lambda}_{0 y} \leq 0.3$, becomes somewhat large in accordance with the increases of $K$ and $\bar{\lambda}_{0 y}$. Therefore, the effective column length factor $\beta$ should be found as a function of $K$ and $\bar{\lambda}_{0 y}$. These results are quite different from the elastic buckling theory such as $\beta$ remains constant when $K$ is constant (see Table 1), because the flexural rigidities of columns are considerably small near the buckling loads by the propagation of plastic zones and then the rotational restraints at the tops of columns are variable. According to JSHB, $\beta$ is constant $(=1.5)$ in the ranges where $0<K \leq 5$, and this criteria seems to be conservative in case where $K$ and $\bar{\lambda}_{0 y}$ are small.

From numerous analytical results, the relationships between $\bar{\lambda}_{y}$ and $\bar{\lambda}_{0 y}$ can be set as follows;

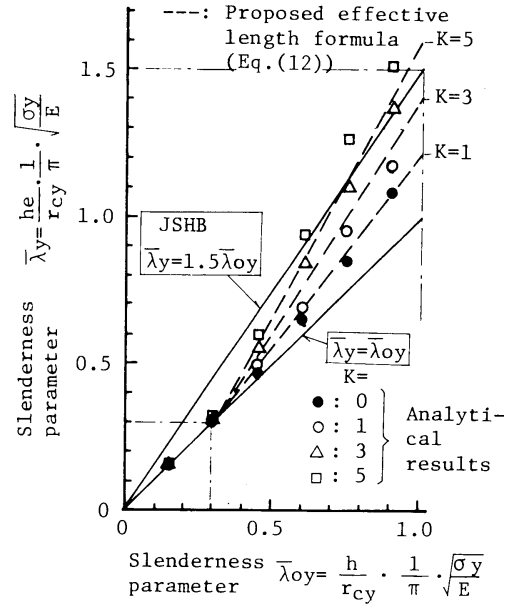

Fig. 12 Relationship between slenderness parameters $\bar{\lambda}_{\text {oy }}$ and $\bar{\lambda}_{y}$

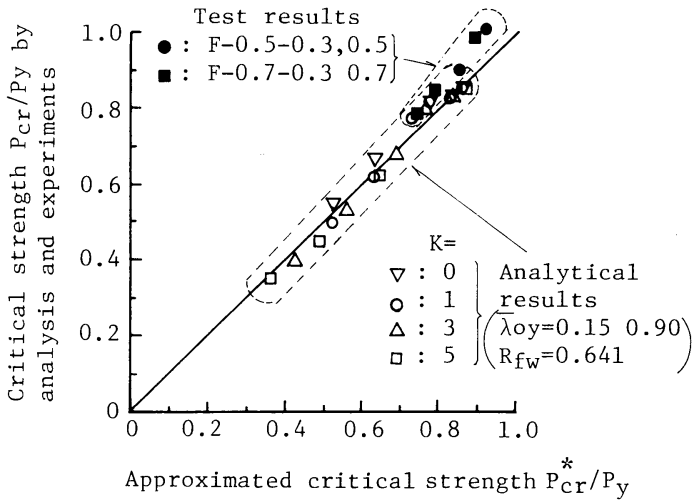

Fig. 13 Comparison of critical strength $P_{c r}^{*} / P_{y}$ calculated by Eq. (16) with analytical and experimental results $P_{c r} / P_{y}$. 


$$
\left.\begin{array}{rr}
\bar{\lambda}_{y} & =\bar{\lambda}_{0 y}, \quad\left(\bar{\lambda}_{0 y} \leq 0.3 \text { and } 0<K \leq 5\right) \\
& =\bar{\lambda}_{0 y} \cdot(8+K) / 7-(3 / 70) \cdot(1+K),\left(0.3<\bar{\lambda}_{0 y} \leq 0.9 \text { and } 0<K \leq 5\right)
\end{array}\right\}
$$

Then, the factor $\beta$ can be calculated by the following equation;

$\beta=\bar{\lambda}_{y} / \bar{\lambda}_{0 y}$

( 2 ) Approximate method for critical strength considering local buckling

As the critical strength obtained by using Eqs. (12) and (13) is the strength of buckling instability of frame, it is necessary to evaluate the critical strength by considering the local buckling of column sections in the extents of smaller slenderness parameter $\bar{\lambda}_{0 y}$. The critical strength $P_{c 1} / P_{y}$ in this region will be approximated by the ultimate strength curve of column in Ref.7) by considering the local buckling as follows ;

$$
\left.\begin{array}{rlrl}
P_{c 1} / P_{y} & =P_{c 0} / P_{y}, & & k_{p l} \geq 1-\left(0.48 \cdot \bar{\lambda}_{y}\right)^{2} \\
& =P_{c 0} / P_{y} \cdot\left\{k_{p l}+\left(0.48 \cdot \bar{\lambda}_{y}\right)^{2}\right\}, & & k_{p l}<1-\left(0.48 \cdot \bar{\lambda}_{y}\right)^{2}
\end{array}\right\}
$$

$P_{c 0} / P_{y}$ is the buckling strength for $\bar{\lambda}_{y}$ in Eq. (12), which can be calculated by the column strength curve of $\mathrm{JSHB}^{1)}$ as follows ;

$$
\left.\begin{array}{rlr}
P_{c 0} / P_{y} & =1.0, & \bar{\lambda}_{y} \leq 0.2 \\
& =1.0-0.545\left(\bar{\lambda}_{y}-0.2\right), & 0.2<\bar{\lambda}_{y} \leq 1.0 \\
& =1 /\left\{0.773+\bar{\lambda}_{y}^{2}\right\}, & 1.0<\bar{\lambda}_{y}
\end{array}\right\}
$$

Thus, the critical strength, $P_{c r}^{*} / P_{y}$, can be obtained by the following equation;

$P_{c r}^{*} / P_{y}=\min \left\{P_{c 0} / P_{y} ; P_{c 1} / P_{y}\right\}$

(3) Verification of approximate method

The final critical strength $P_{c r}^{*} / P_{y}$, approximated by Eqs. (12) (16), was compared with the analytical results in Table 6 and experimental ones in Table 4. The results are summarized in Fig. 13.

The values of $P_{c r}^{*} / P_{y}$ given by Eq. (16) are well coincided with the analytical ones within the errors \pm $4 \%$ and somewhat underestimate the test results by $3 \sim 10 \%$, but give the lower bound of them.

Thus, this proposition seems to be practical and it is, therefore, concluded that an approximate method to estimate the lower bounds of critical strength, predicated in this paper, will be useful for establishing the limit state design methods of thin-walled steel frames.

\section{CONCLUSION}

In this paper, the critical strength of thin-walled portal frames subjected to vertical loads were clarified by analytical and experimental studies. The main conclusions can be summarized as follows;

(1) The lower bounds of critical strength of frames were clarified, i. e. the ultimate strength for local buckling of a column section was predominant in the range of smaller slenderness parameter $\bar{\lambda}_{0 y}$, whereas the overall buckling was governed by the strength of frames with larger $\bar{\lambda}_{0 y}$.

(2) The formulae for effective column length of portal frames within the ranges of $0<K \leq 5$ and $0<\bar{\lambda}_{0 y} \leq 0.9$ were proposed on the basis of buckling instability of frame.

( 3 ) An approximate method for estimating the critical strength of portal frames by considering the local buckling of column sections was proposed through the applications of the column strength curves of JSHB

(4) The critical strengths calculated by the above propositions well coincided with the analytical and experimental results.

(5) These propositions will be able to apply to the limit state design of thin-walled frames.

\section{ACKNOWLEDGMENTS}

The authors would like to express the appreciations to Mr. K. Ohgaki, Post Graduate Student of Osaka City University, for his helps in conducting the experimental study. 


\section{REFERENCES}

1) Japan Road Association: Specifications for Highway Bridges (JSHB), Feb., 1980.

2) European Convention for Constructional Steelwork : European Recommendations for steel construction, March 1978.

3) ECCS : Eurocode 3, Common Unified Code of Practice for Steel Structures, Draft, July 1983.

4) DIN 18800 Teil II : Norm-Voriage, Stabilitätsfalle im Stahlbau, Knicken und Stabwerken, Juli 1979.

5) Shultz, G : Die Traglastberechnung von planmäßig mittig belasteten Druckstaben aus Baustahl unter Berücksichtigung von geometrischen und struktrellen Imperfectionen, Dissertation, T. H. Graz, Juli 1968.

6) Usami, T., Fukumoto, Y. and Aoki, T. : Tests on the Interaction Strength between Local and Overall Buckling Welded Box Columns, Proc. of JSCE, No. 308, pp. 47 58, April 1981.

7) Nakai, H., Kitada, T. and Miki, T. : Interaction Curve of Thin-Walled Box Stub-Columns subjected to Compression and Bending for applying to Overall Buckling Analysis of Columns, Proc. of JSCE, Structural Eng. /Earthquake Eng., Vol.2, No. 2, pp. 311 s $\sim 318$ s, Oct. 1985.

8) Johnston, B. G. : Guide to Stability Design Criteria for Metal Structures, John Willey \& Sons, Chapter 3, pp. $26 \sim 80,1976$.

9) Galambos, T. V. : Structural Members and Frames, Prentice-Hall, New York, 1968.

10) Wakabayashi, M. and Matsui, C. : Experimental Studies on the Elastic-Plastic Stability of Steel frames, Part 1 3, Trans. of AIJ, Jan, pp. 11 21, Feb., pp. 17 27, and March, pp.9 19, 1972.

11) McNamee, B. M. and Le-Wu Lu : Inelastic Multistory Frame Buckling, Proc. of ASCE, Vol.98, No. ST 7, pp. 1613 1631, July 1972 .

12) Nakai, H., Emi, S. and Miki, T. : A Study on In-Plane Buckling Collapse of Thin-Walled Steel Frames subjected to Vertical Loads, Proc. of Structural Engineering, Vol.31 A, pp.79 92, March 1985.

13) Timoshenko, S. P. and Gere, J.M. : Theory of Elastic Stability, Second Edition, McGraw Hill, 1961.

14) Nakai, H., Kawai, A., Yoshikawa, O., Kitada, T. and Miki, T. : A Survey on Steel Piers, Bridge and Foundation Engineering, Vol. 16, June, pp. 35 40. and July, pp. 43 49, 1982.

15) Nakai, H., Kitada, T. and Miki, T. : Ultimate Strength of Thin-Walled Box Stub-Columns, Proc. of JSCE, Structural Eng. /Earthquake Eng., Vol. 2, No. 1, pp. 1 s 11 s, April 1985.

(Received May 16 1985) 